\title{
Advanced COPD patients under Home Mechanical Ventilation and/or Long Term Oxygen Therapy: Italian Healthcare Costs
}

\author{
M. Vitacca1 ${ }^{1}$ L. Bianchi1 ${ }^{1}$ A. Bazza1', E.M. Clini²
}

ABSTRACT: Advanced COPD patients under Home Mechanical Ventilation and/or Long Term Oxygen Therapy: Italian Healthcare Costs. M. Vitacca, L. Bianchi, A. Bazza, E.M. Clini.

Background and Aim. Little information is available on healthcare costs for patients with very severe chronic obstructive pulmonary disease. The aim of the current work was to evaluate Italian healthcare costs in these patients.

Methods. Prospective 1-year analysis was assessed in three subgroups of patients; non-invasively ventilated $(n=30)$; invasively-ventilated $(n=12)$ and on longterm oxygen therapy $(n=41)$. Acute costs for care were a sum of fees for doctor's consultations, admissions to hospital (ward and intensive care units) and emergency drugs. Chronic costs were the sum of costs for pharmacotherapy and home ventilation and/or oxygen care.

Results. Mean cost/day/patient was 96 $\pm 112 €$ (range $9-526 €)$, with acute costs accounting for $72 \%$ and chronic costs for $28 \%$ of the total cost burden, with no significant differences in costs associated with the three subgroups. Acute costs had a non-normal distribution (range 0 to 510€) being cost for hospitalisation the highest cost burden with more than $30 \%$ of acute care costs attributed to only a small segment of patients. Chronic care costs were also unevenly distributed among the various groups (ANOVA $p=0.006$ ), being home oxygen supply the highest cost burden.

Conclusions. The current Health Care System is in urgent need for a reassessment of the high cost burden associated with hospitalisations and home oxygen supply. Monaldi Arch Chest Dis 2011; 75: 4, 207-214.

Keywords: Home Mechanical Ventilation, Hypoxemia, Hypercapnia, Long-term care programs.

1 Division of Pulmonary Rehabilitation, Fondazione Salvatore Maugeri, IRCCS, Lumezzane (BS), Italy,

2 University of Modena and Rehabilitation Hospital Villa Pineta, Pavullo (MO), Italy.

The work was performed at the Respiratory Unit of the Fondazione Salvatore Maugeri, Lumezzane (BS), Italy.

Correspondence: Michele Vitacca, Division of Pulmonary Rehabilitation, Fondazione Salvatore Maugeri IRCCS, Via Giuseppe Mazzini 129, 25066Lumezzane (Brescia), Italy; e-mail:vitacca@fsm.it

\section{Introduction}

Worldwide, chronic obstructive pulmonary disease (COPD) affects $9.8 \%$ of men and $5.6 \%$ of women [1]. In Italy, an estimated 2.6 million men and women have COPD [2] with prevalence rates ranging from $11 \%$ to $18 \%$ according to different criteria used for diagnosis [1]. Prevalence of the most severe patients using oxygen therapy or home mechanical ventilation (HMV) has been described as $0.4 \%$ [1] and 6.6 cases per 100.000 persons, respectively. $34 \%$ of HMV users are patients with COPD [3].

The cost for COPD is a burden for the national Health Care System (HCS) which increases directly with the severity of the disease.

Hospitalisations and pharmacotherapy are the most frequently reported large costs [1]. Annual costs for European patients have been reported to be in the range of 151-3,912€ [4] Most of the severe COPD patients still benefit from oxygen and ventilator support $[3,5]$.
The time course of the disease completely differs in COPD and chronic respiratory failure (CRF) patients compared with patients with cancer: indeed, COPD patients present progressive limitation of functions, recurrent exacerbations and hospitalisations [6] which, in turn, further increases disability and burden of costs until death [7]. Hospital admissions occur mostly in a period of 3.5 years with a high percentage in the six months preceding death [8].

Very severe COPD patients at high risk of death needing continuity of care involve a lot of resources and money in any country. Currently there is no unique model to provide high-quality standard of care in these patients [9] thus there is no evidence either for its efficacy or costs. Despite increasing amount of prognostic indicators which can help identify COPD patients at high risk of death, prognosis in these patients remains uncertain and extremely variable. Literature and guidelines offer poor recommendations for the provision of care in most severe patients with COPD [10]. 
Otherwise, the policy focus on identifying a time point for transition to case management care has little resonance for people with very severe COPD [11]. Careful assessment of possible supportive and advanced care needs should be triggered at key disease milestones along a lifetime journey with COPD, in particular after hospital admission for an exacerbation [11]. The current study was aimed at prospectively reporting a 1-year costs analysis for Italian HCS in a subgroup of very severe COPD patients on HMV and/or long-term oxygen therapy (LTOT).

\section{Methods}

\section{Patients Population}

All hypoxemic (less than $60 \mathrm{mmHg}$ ) and hypercapnic (more than $45 \mathrm{mmHg}$ ) COPD patients with clinical prescription for HMV [delivered either invasively (IMV) or non-invasively (NIMV)] and/or LTOT discharged from the Respiratory Department of Fondazione Salvatore Maugeri IRCCS, Lumezzane (Italy) in the period between May 2004 and March 2007 were considered. Very severe COPD was defined when a patient presented at least two of the following criteria, according to [12]:

- forced expiratory volume at first second $\left(\mathrm{FEV}_{1}\right)$ predicted $<30 \%$ prd,

- oxygen dependence,

- one or more hospitalisations in the year preceding the study,

- left heart failure or other co-morbidities,

- weight loss in the last 6 months or chronic cachexia,

- decreased functional status,

- increasing dependence during activities of daily life,

- 70 years old.

The study was conducted in accordance with the Declaration of Helsinki. Our Ethics Committee approved the protocol. All patients signed the informed consent.

\section{Clinical Evaluation}

Anthropometric and functional data were recorded for all patients at baseline. Pre-morbidity Life Style (PLS) score (from $0=$ employed with maximal level of autonomy to $4=$ bedridden), lung volumes, arterial blood gases and number of self reported co-morbidities [13] were also assessed. Mortality rate, number of exacerbations requiring use of antibiotics and/or oral steroids, number of admissions to hospital, intensive care unit (ICU), and emergency room (ER), number of urgent calls to the general practitioner (GP) were also recorded during the 1-year follow-up period. The long-term care programme consisted in: discussion of preferences for life sustaining treatments, holistic care with prescription of home devices and reconditioning activity to alleviate fatigue and improve quality of life (QoL), activation of community health services, help for caregiver burden and 3 months outpatient visits in a dedicated office; unstructured contacts by phone were possible when requested by patient or caregiver.

\section{Costs Analysis for the Health Care System}

1. acute costs (AC) expressed as unitary reimbursement (UR) by the national Diagnosis-Related-Group per single performance related to acute events such as urgent GP consultations $(30 €)$, ER visits $(62 €)$, medical wards admissions (4.000€), ICU admissions for MV use $>96 \mathrm{~h}$ and with $(66.661 €)$ or without $(10.113 €)$ tracheostomy operation need. Final costs were computed by multiplying the number of events (stays or activities) for the cost per prescription as referred above;

2. chronic costs (CC) expressed as UR for home care computed as daily cost related to LTOT $(0,006 €$ per liter of oxygen), NIMV rent (3.93€/day) and IMV rent (12.5€/day). Final costs were computed by multiplying the number of prescriptions (litres of oxygen/day and days of rent) for the cost per unit as referred above.

Single drug piece cost was derived from the current marketed costs; final costs (both for acute exacerbations and for usual chronic therapy) were computed by multiplying the number of inhalers used for the unitary cost/piece. Chronic personnel costs due to nurse home care were not computed because only 15 out $83(18.1 \%)$ received episodic home interventions while none received rehabilitative admissions.

\section{Statistical Analysis}

Statistical analysis was performed using package SPSS software (release 12.0. SPSS, Chicago, Il). Descriptive data is expressed as mean, standard deviation (SD) or standard error of mean (SEM), range or percentages where appropriate. One-way analysis of variance (ANOVA) for multiple comparisons with Bonferroni's correction was applied to assess group differences for all variables. The assumption for the equality of variances for the groups was tested by means of the Levene test for homogeneity of variances. In cases of inequality of the variances of dependent variable, the Welch and Brown-Forsythe statistics were used as alternatives to the F test. An unpaired two-tailed $t$-test was used to assess differences in variables between NIMV and IMV patients. A $p$-value $<0.05$ was considered statistically significant.

\section{Results}

\section{Patients' Population}

$83(51 \%)$ out of 163 discharged patients with COPD and Chronic Respiratory Failure (CRF) met inclusion criteria and were enrolled. The mean follow-up was $10 \pm 3.4$ months due to 23 patients $(7,4$ and 12 for NIV, IMV and LTOT respectively) who 
died before the first year of observation. The causes of death did not differ among groups: cardiovascular reasons in the $52 \%$, sepsis in 30\% and end stage respiratory causes in the remaining $18 \%$ of the cases.

Table 1 shows the anthropometric, clinical and functional data of the study population. All patients were in severe stages of COPD and had global CRF and respiratory muscles impairment. They showed severe disability as shown by the PLS, MRC scores and number of self-reported comorbidities. The majority of them were on LTOT since $>4$ years. Study population was divided into 3 groups according to the type of home treatments:

1) NIMV $=30$ patients $(36.1 \%)$,

2) $\mathrm{IMV}=12$ patients $(14.5 \%)$, and

3) spontaneously breathing on LTOT $=41$ patients $(49.4 \%)$.
Years of LTOT, hospitalisations/year, previous ICU admissions, age, level of $\mathrm{FEV}_{1}$ and dependency were different among groups. Clinical outcomes are detailed in table 2.

\section{Causes for Hospital Admissions}

As shown in table 1 total number of co-morbidities and in particular cardiovascular ones were not different among groups. 85\% of hospital admissions were due to primary respiratory causes (relapses of COPD, pneumonia and pulmonary embolism in $50 \%, 30 \%$ and $20 \%$ of the cases). The remaining admissions were computed to cardiovascular reasons. No differences were found for causes of admission among the three groups of patients.

Table 1. - Characteristics of Patients' Population

\begin{tabular}{|c|c|c|c|c|}
\hline & NIMV & IMV & LTOT & $\begin{array}{c}\text { ANOVA } \\
p\end{array}$ \\
\hline Patient Number $(\%)$ & $30(36.1)$ & $12(14.5)$ & $41(49.4)$ & $n s$ \\
\hline Age, y & $67 \pm 10$ & $72 \pm 6$ & $73 \pm 8$ & 0.027 \\
\hline Males, $\mathrm{n}$ & 19 & 8 & 34 & $n s$ \\
\hline Ex smokers, $\mathrm{n}$ & 23 & 6 & 29 & $n s$ \\
\hline Current smokers, $\mathrm{n}$ & 7 & 0 & 5 & $n s$ \\
\hline Patients with BMI $<24\left(\mathrm{~kg} / \mathrm{m}^{2}\right), \mathrm{n}$ & 13 & 10 & 11 & $n s$ \\
\hline Hospitalizations/year, $\mathrm{n}$ & $1.70 \pm 1.06$ & $2.92 \pm 1.24$ & $1.54 \pm 1.33$ & 0.011 \\
\hline Previous admission in ICU, (\%) & 50 & 67 & 32 & 0.01 \\
\hline Patients with at least one hospitalization in the last year, $\mathrm{n}$ & 25 & 17 & 41 & $n s$ \\
\hline Symptoms, y & $11 \pm 8$ & $13 \pm 7$ & $11 \pm 7$ & $n s$ \\
\hline Dyspnea MRC scale $\geq 2(\%)$ & 30 & 33 & 41 & $n s$ \\
\hline LTOT, y & $4.7 \pm 2.92$ & $6.9 \pm 4.2$ & $3.5 \pm 2.9$ & 0.011 \\
\hline $\mathrm{FEV}_{1}, \%$ prd & $32 \pm 14$ & $19 \pm 2.0$ & $41 \pm 20$ & 0.010 \\
\hline $\mathrm{VC}, \%$ prd & $44 \pm 21$ & $32 \pm 7.0$ & $58 \pm 21$ & $n s$ \\
\hline $\mathrm{PaO}_{2}, \mathrm{mmHg} *$ & $52 \pm 5$ & $51 \pm 7.0$ & $53 \pm 5$ & $n s$ \\
\hline $\mathrm{PaCO}_{2}, \mathrm{mmHg} *$ & $49 \pm 9$ & $54 \pm 7.0$ & $48 \pm 9$ & $n s$ \\
\hline $\mathrm{pH} *$ & $7.37 \pm 0.02$ & $7.35 \pm 0.01$ & $7.38 \pm 0.02$ & 0.046 \\
\hline MIP, \% prd & $44 \pm 14$ & $30 \pm 10$ & $41 \pm 19$ & $n s$ \\
\hline MEP, \% prd & $46 \pm 20$ & $38 \pm 10$ & $47 \pm 17$ & $n s$ \\
\hline Co-morbidities, $\mathrm{n}$ & $2.17 \pm 1.12$ & $2.40 \pm 1.08$ & $2.25 \pm 1.59$ & $n s$ \\
\hline PLS & $2.38 \pm 0.81$ & $3.07 \pm 0.75$ & $2.01 \pm 0.82$ & 0.0001 \\
\hline
\end{tabular}

BMI indicates body mass index; $F E V_{1}$ forced expiratory volume at first second; IMV, invasive mechanical ventilation; LTOT, long-term oxygen therapy; MEP, maximal expiratory pressure; MIP, maximal inspiratory pressure; MRC, Medical Research Council; NIMV, non invasive mechanical ventilation; PLS indicates premorbidity lifestyle score; VC, vital capacity; *Indicates arterial blood gases measured in room air: $\mathrm{PaCO}_{2}$, carbon dioxide arterial tension and ph; $\mathrm{PaO}_{2}$, arterial oxygen tension.

Table 2. - Clinical Outcomes

\begin{tabular}{|c|c|c|c|c|}
\hline & $\begin{array}{l}\text { NIMV } \\
(n=30)\end{array}$ & $\begin{array}{c}\text { IMV } \\
(n=12)\end{array}$ & $\begin{array}{c}\text { LTOT } \\
(n=41)\end{array}$ & $\begin{array}{c}\text { ANOVA } \\
p\end{array}$ \\
\hline Mortality rate $(\%)$ & 23 & 33 & 29 & $n s$ \\
\hline N. of exacerbations/month (mean \pm sd) & $0.58 \pm 0.70$ & $0.55 \pm 0.91$ & $0.88 \pm 1.01$ & $n s$ \\
\hline N. of admissions in hospital/month (mean \pm sd) & $0.26 \pm 0.24$ & $0.15 \pm 0.16$ & $0.29 \pm 0.33$ & $n s$ \\
\hline Number of admissions in ER/month (mean \pm sd) & $0.12 \pm 0.18$ & $0.15 \pm 0.18$ & $0.13 \pm 0.23$ & $n s$ \\
\hline N. of urgent calls/month to GP (mean \pm sd) & $0.16 \pm 0.23$ & $0.07 \pm 0.12$ & $0.24 \pm 0.42$ & $n s$ \\
\hline
\end{tabular}

ER indicates emergency room; GP, general practitioner; ICU, intensive care unit; IMV, invasive mechanical ventilation; LTOT, long-term oxygen therapy; NIMV, non-invasive mechanical ventilation. 
Costs Analysis for the Health Care System

The overall mean cost/day/patient was $96 \pm 112 €$ (range $9-526 €$ ) consisting of $72 \%$ AC and $28 \%$ CC of the average total cost per patient (figure 1 left panel) and totalling up to $34,820 €$ per patient per year $(42,340 €, 23,725 €$ and 32,120 in NIMV, IMV and LTOT, respectively).

There was no significant difference in the total cost among groups $(117 \pm 134 €, 66 \pm 39 €$ and $88 \pm 106 €$ in NIMV, IMV and LTOT, respectively) (figure 1 right panel). However, considering only the costs for standard ward, cutting off the ICU costs accounting for high care expenses in a few number of patients, the overall mean cost/day/patient decreases to $56 \pm 39 €(-42 \%)$ computing for a cost of $20,440 €$ per patient per year.

\section{Acute Costs}

AC per patient weren't statistically different in the three groups (table 3) accounting for $75 \%$ of total costs in NIMV and LTOT, and about $50 \%$ in IMV (figure 1 right panel).

Average daily AC $(68 \pm 109 €)$ were non-normally distributed among patients with wide range of expense (0-510€) (figure 2 top panel). Analysis of frequency of $\mathrm{AC}$ within all population showed that 67 out of 83 patients $(80.7 \%)$ cost $<100 € /$ day (figure 2 top panel). In particular, only five patients $(6 \%)$ exceeded the $95^{\text {th }}$ percentile of mean daily cost and accounted for nearly $30 \%$ of the cumulative daily $\mathrm{AC}$ of the whole population $(1659 / 5723 €)$. These five patients had, when compared to the remaining ones, a longer time of oxygen use, a worse $\mathrm{FEV}_{1}, \mathrm{CV}, \mathrm{PaO}_{2}$ and $\mathrm{PaCO}_{2}$. Furthermore, they presented a higher healthcare cost for repeated hospitalizations and ER admissions/y, ICU stay and relapses at home.

A further analysis among groups also confirmed that daily AC in NIMV patients (figure 2 left bottom) and LTOT (figure 2 right bottom) ranged from 0 to $600 €$ with few patients in both groups, using the greatest amount of expense. Conversely, AC in IMV patients ranged between 0 and $116 € /$ day (figure 2 middle bottom). Hospitalisation (either in the ward or in ICU) represented the greatest amount of expense, being due to at least i) one episode during the study period (table 3 ) in $87 \%$ NIMV, 58\% IMV and 73\% LTOT patients respectively, and ii) one ICU admission in 13/63 (21\%) hospitalised patients more frequently occurring in NIMV and LTOT (23 and 12\%, respectively) than in IMV group (8\%). Seventeen ICU admissions interested 12 patients. Drugs and other costs (ER accesses and GP urgent calls) were $<3 \%$.

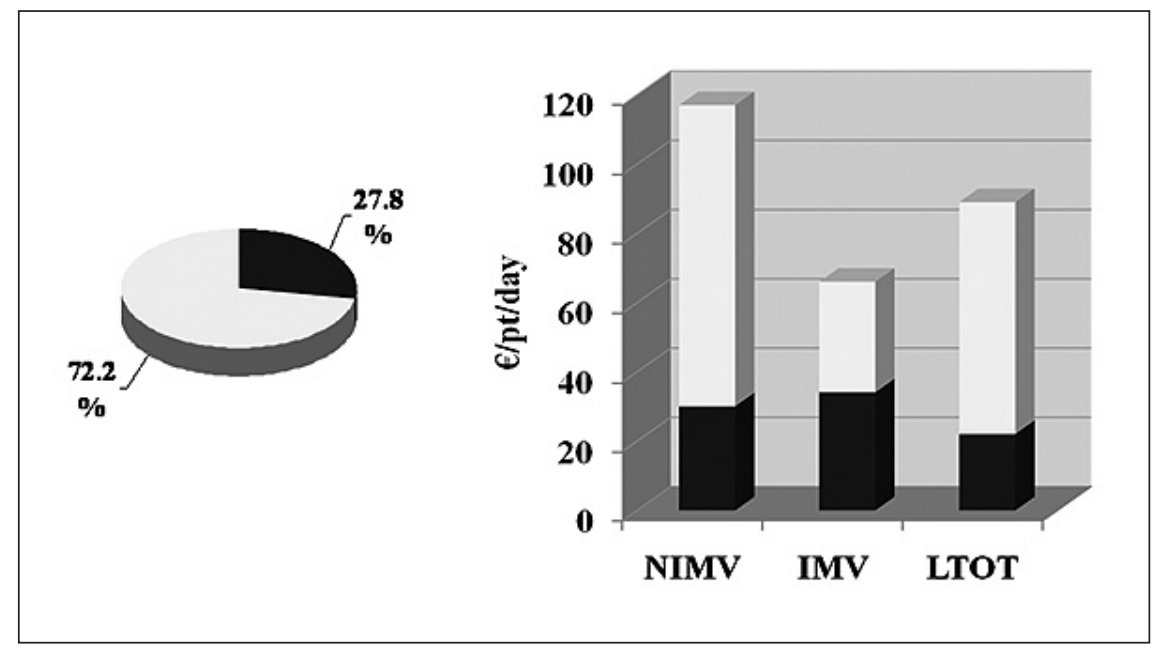

Fig. 1. - Health Care System burden of acute (white) and chronic (dark) costs. Costs are expressed as average cost/patient/day for the whole group (left part) and by three different sub-groups [NIMV, IMV and LTOT (right part)].

IMV indicates invasive mechanical ventilation; NIMV, non-invasive mechanical ventilation; $L T O T=$ long-term oxygen therapy.

\section{Chronic Costs}

Figure 3 shows the frequency distribution of $\mathrm{CC}$ in the total population and by group. 4/83 patients (5\%) exceeded the $95^{\text {th }}$ percentile of average daily cost and accounted for $13 \%$ of the cumulative daily $\mathrm{CC}$. $\mathrm{CC}$ were unevenly distributed among groups $(\mathrm{p}=0.006) \quad$ table 4) being expenses in the LTOT (figure 3 right bottom) lower than in NIMV $(p=0.038)$ (table 4 and figure 3 left bottom) and IMV ( $\mathrm{p}=0.021)$ group (table 4 and figure 3 middle bottom). As expected, IMV group used major resources for HMV rent

Table 3. - Average Acute Cost (€/patient/day) of Items by Patient Groups

\begin{tabular}{lcccc}
\hline$(€ /$ patient/day) & NIMV & IMV & LTOT & ANOVA \\
& $(\boldsymbol{n}=\mathbf{3 0})$ & $(\boldsymbol{n = 1 2 )}$ & $(\boldsymbol{n}=\mathbf{4 1})$ & $\begin{array}{c}\boldsymbol{p} \\
\text { Hospital admissions }\end{array}$ \\
ICU admissions & $34 \pm 32$ & $24 \pm 29$ & $36 \pm 40$ & 0.59 \\
Drugs (antibiotics, systemic steroids) & $52 \pm 111$ & $7 \pm 24$ & $29 \pm 84$ & 0.31 \\
Others & $0.8 \pm 0.7$ & $0.7 \pm 0.7$ & $0.8 \pm 0.9$ & 0.83 \\
Total AC/patient & $0.5 \pm 0.5$ & $0.3 \pm 0.4$ & $0.5 \pm 0.7$ & 0.78 \\
\hline
\end{tabular}

$A C$ indicates acute costs; ICU, intensive care unit; IMV, invasive mechanical ventilation; LTOT, long-term oxygen therapy; NIMV, non-invasive mechanical ventilation. 


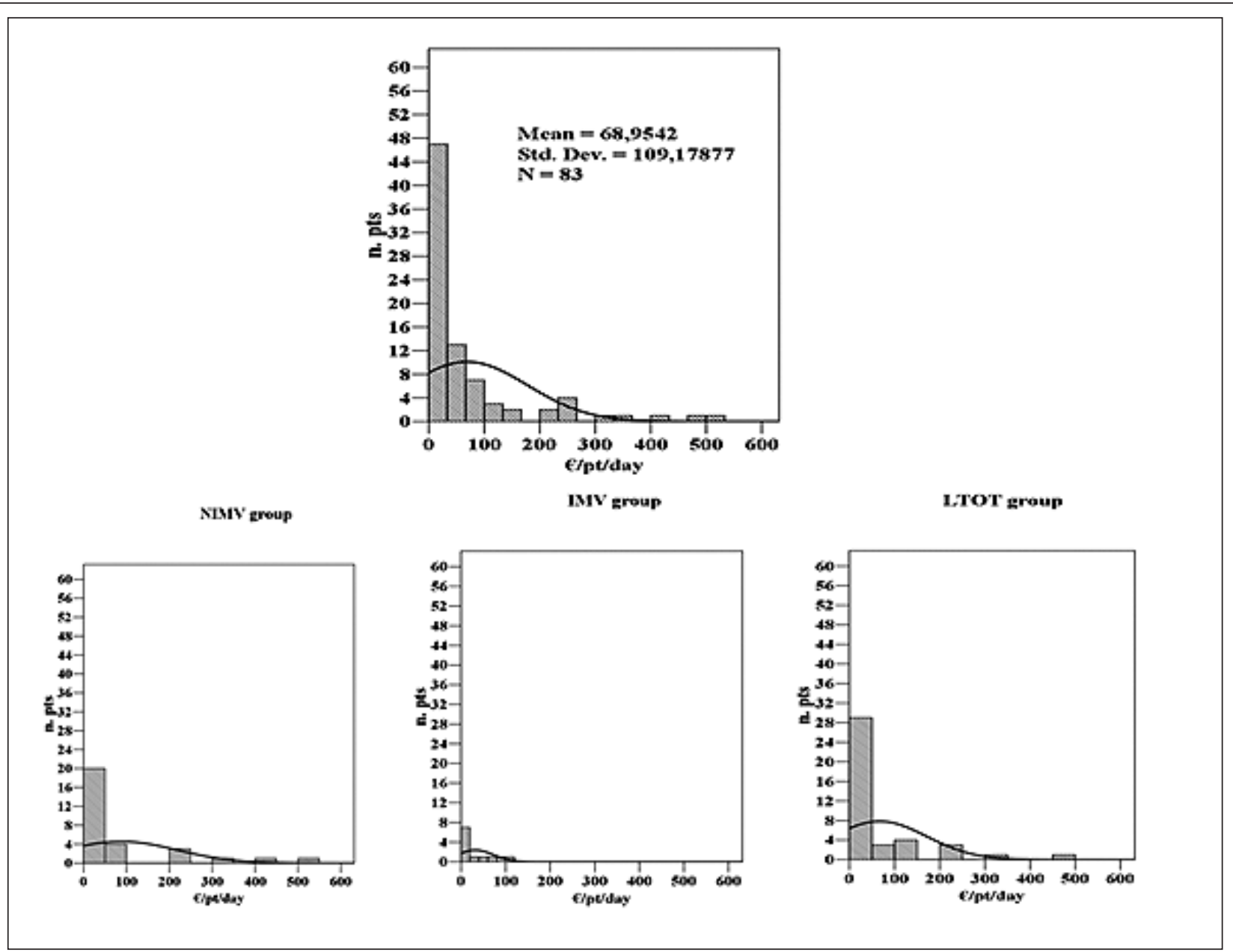

Fig. 2. - Analysis of frequency of acute costs for the three different sub-groups (NIMV, IMV and LTOT). A minority of patients $(\mathrm{n}=4 ; 4.8 \%)$ exceeded the $95^{\text {th }}$ percentile of mean daily cost and accounted for nearly $30 \%$ of the cumulative daily acute costs of patients' population. $I M V$ indicates invasive mechanical ventilation; NIMV, non-invasive mechanical ventilation; LTOT = long-term oxygen therapy.

when compared to NIMV. In all groups, home oxygen supply represented the greatest cost $(70 \%$, $47 \%$ and $77 \%$ of the total CC for NIMV, IMV and LTOT groups, respectively) while there were no differences among groups in the items distribution.

\section{Discussion}

Our study shows that the costs for care afforded by HCS for very severe patients with COPD and CRF are considerably high.

The expense for acute events, mainly hospitalisations, was prevalent $(72 \%)$ compared with the home care costs. Only $5 \%$ of patients used $>30 \%$ of the cumulative daily costs for acute care. Despite this CC was lower in spontaneously breathing patients on LTOT when compared with ventilated patients, oxygen supply represented the greatest expense.

COPD has a substantial HCS burden in developed countries [14] due to direct and indirect medical expenses, with palliative care being a huge contributor [1]. Few studies quantified the real economic burden in a group of patients with very severe COPD who have been prescribed home oxygen and/or HMV. In this group of patients, hospitalisation occurs more frequently in the final years of life [15]. Since the time course and prog- nosis of COPD in this subgroup of patients are very difficult to predict, the boundary between standard treatment and case management care is still undefined $[11,12]$.

The main finding of the current study is the reported average daily cost per patient in Italy for the COPD population, which adds up to $34,820.00 €$ per year. This burden is not comparable to previous data reported in other countries for severe COPD (4,400.00 $\pm 2,560.00 €$ mean annual cost/patient) [15-28] and in Italy (mean cost/patient/ year around $2450 €$ ) [29, 30]. This difference in costs is most certainly related to the non homogeneous characteristics of our patients' population in comparison with previous studies [15-30] in which younger patients (age range 58-70 years) were included. Indeed, our patients were older $(71 \pm 8$ years old on average) and in a very advanced stage of the disease on the basis of $\mathrm{FEV}_{1}$ level $(30 \% \pm 9)$ and presence of CRF (in $100 \%$ of cases), with $51 \%$ of them under either home IMV or NIMV.

To our knowledge, only the study by Clini et al. [31] analysed the costs in patients with functional characteristics similar to those of our population. They estimated an average annual cost per patient of $8,240.00 €(8,660.00 €$ for in LTOT+ NIMV and 7,818.00€ in LTOT group). This amount is almost twice as high as has been report- 


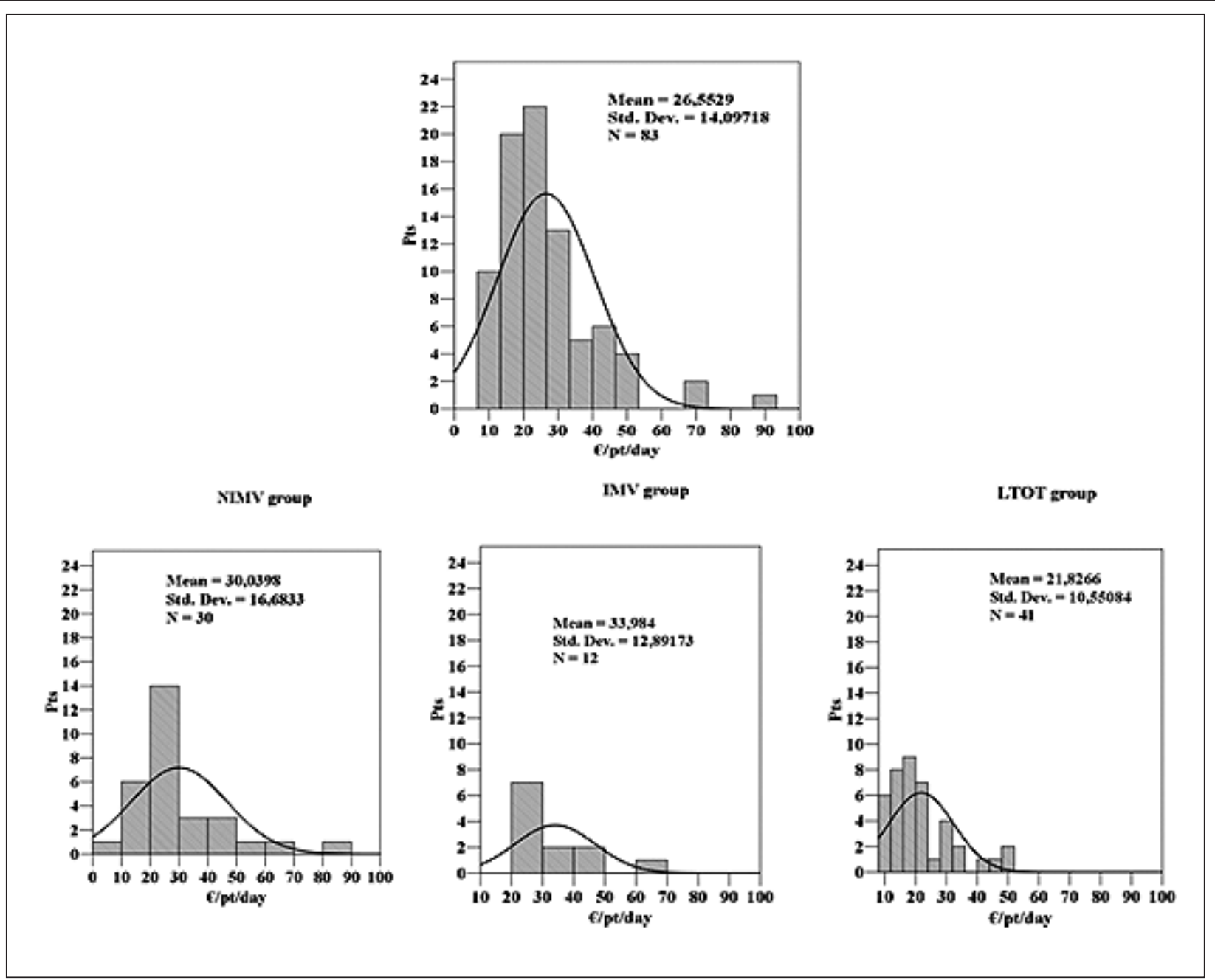

Fig. 3. - Analysis of frequency of chronic costs for the three different sub-groups (NIMV, IMV and LTOT). A minority of patients $(\mathrm{n}=4$; $4.8 \%$ ) exceeded the $95^{\text {th }}$ percentile of average daily cost and accounted for $13 \%$ of the cumulative daily expenses for chronic care.

IMV indicates invasive mechanical ventilation; NIMV, non-invasive mechanical ventilation; LTOT = long-term oxygen therapy.

ed in previous studies, and also vastly different from the values found by us.

The current study has confirmed that hospitalisation is the most important cost-driver representing $72 \%$ of care burden for severe and advanced COPD, as compared with $58 \%$ of previous reports [17-31]. Moreover, for the first time it describes hospital costs both in standard ward and in ICU (31\% and $39 \%$ of the total average cost/year/patient, respectively). It is surprising that no significant difference in the AC could be detected among the three patients' groups despite patients having discrete variability in CRF. This result may be explained by the fact that patients admitted to ICU more often belonged to NIMV and LTOT groups, thus reflecting their lower clinical stability when compared to IMV patients: the 24-h use of MV and consequent higher home care assistance resulted in a better stabilization of both clinical course and blood gases. Indeed, in advanced COPD patients we could speculate that tracheostomy might be preferred in term of stabilisation of AC (i.e. reduction in ICU admissions) opening ethical issues and mandatory respect about patient's decisions on his/her QoL. The relatively high percentage of tracheostomised COPD patients in the present study may be surprising but reflects the Italian health habits to not refuse admission in ICU also in patients previously treated with oxygen and NIMV.

Moreover, the variability in the AC confirms that functional data alone is not sufficient to establish illness severity and are poor predictors of COPD time course. Consequently, these results cannot predict the use of resources. The higher average AC in NIMV and LTOT groups may be also explained by the high cost of tracheostomy performed in ICU according to patient's necessity, cost not computed in the invasive tracheostomised patients.

Finally, our study has shown that the annual cost/patient related to chronic home care was 5fold higher when compared with previous data $(9,800.00 €$ vs. $1,845.00 €)[20-28,30]$ and 2 -fold higher than data by Clini et al. [31]. The highest $\mathrm{CC}$ were mainly due to the higher oxygen volume (time and flow), use of medications and rent expense for MV. The statistically significant lower cost between LTOT and ventilation (both IMV and NIMV) in the chronic care costs is entirely due to the rent of ventilator machine.

Given that our studied population is similar to that described by Andersson et al. [8] we might 
Table 4. - Average Chronic Cost (€/patient/day) of Items by Patient Groups

\begin{tabular}{lcccc}
\hline$(\boldsymbol{€} /$ patient/day) & NIMV & IMV & LTOT & ANOVA \\
& $(\boldsymbol{n}=\mathbf{3 0})$ & $(\boldsymbol{n = 1 2 )}$ & $(\boldsymbol{n = 4 1 )}$ & $\boldsymbol{p}$ \\
\hline LTOT service & $21 \pm 16$ & $16 \pm 13$ & $17 \pm 10$ & 0.33 \\
Drugs (inhalation therapy) & $5 \pm 1$ & $6 \pm 1$ & $5 \pm 1$ & 0.38 \\
HMV service & $4 \pm 0$ & $12 \pm 0$ & n.a. & n.a. \\
Total CC/patient & $30 \pm 17^{*}$ & $34 \pm 1 \S$ & $22 \pm 10$ & 0.006 \\
\hline
\end{tabular}

CC indicates chronic costs; HMV, home mechanical ventilation; IMV, invasive mechanical ventilation; LTOT, long-term oxygen therapy; $n . a$. , not available; NIMV, non-invasive mechanical ventilation.

*vs. LTOT $\mathrm{p}=0.038 ; \S$ vs. LTOT $\mathrm{p}=0.021$ (multiple comparison with Bonferroni correction).

Comparison of HMV cost between the two groups of ventilated patients - NIMV and IMV - was not performed because it was assumed to be the same in each patient.

speculate that our cost analysis would help the HCS to predict budgets and costs-analysis and discussing the implications on care strategies- in this particular subset of patients, for whom the 1-year expected expense can be extended to the estimated time of survival (about 4 years).

The shortcomings of this study, which may prevent direct comparisons with other reports and generalisation, include the small sample size, heterogeneity of clinical histories of enrolled patients, and patient cohort obtained from only one Italian hospital. Furthermore, costs might have changed across years while Diagnostic Related Groups reimbursement does not necessarily reflect real costs of individual treatment. Also in this study, home ventilator disposables or routine laboratory tests costs were not considered. Future studies need to calculate indirect cost related to patients/families.

In conclusion, since transition to case management care often impractical in COPD, holistic approach of supportive care is necessary during the patient's disease course [11].

Our findings suggest that health costs in very severe patients with COPD represent a substantial burden for HCS.

The current study offers details about the cost of this subset of patients and shows general calculations that could be extrapolated to more precisely describe the societal impact. Future studies should address the appropriate use and provision of HCS resources, addressing in particular new strategies that could reduce the oxygen-related costs (incorrect prescription, overuse, low compliance, use of cheaper modality of supply) and hospital admissions (structured follow-up, tele-assistance) as the greatest expenses in this population.

Acknowledgements: The Authors thank Dr. Alessandro Bettini for the English revision of the manuscript.

\section{References}

1. Mannino DM, Buist S. Global burden of COPD: risk factors, prevalence, and future trends. Lancet 2007; 370: 765-73.

2. Dal Negro R, Rossi A, Carver I. The burden of COPD in Italy: results from the Confronting COPD survey. Respir Med 2003; 97 Suppl C: S43-50.
3. Lloyd-Owen SJ, Donaldson GC, Ambrosino N, et al. Patterns of home mechanical ventilation use in Europe: results from the Eurovent survey. Eur Respir J 2005; 25: 1025-31.

4. Chapman KR, Mannino DM, Soriano JB, et al. Epidemiology and costs of chronic obstructive pulmonary disease. Eur Respir J 2006; 27: 288-97.

5. Clini EM, Ambrosino N. Nonpharmacological treatment and relief of symptoms in COPD. Eur Respir $J$ 2008; 32: 218-28.

6. Lynn J. Perspectives on care at the close of life serving patients who may die soon and their families: the role of hospice and other services. JAMA 2001; 285: 925-32.

7. Teno JM, Weitzen S, Fennell ML, Mor V. Dying trajectory in the last year of life: does cancer trajectory fit other diseases? J Palliat Med 2001; 4: 457-64.

8. Andersson FL, Svensson K, Gerhardsson de Verdier M. Hospital use for COPD patients during the last few years of their life. Respir Med 2006; 100: 1436-41.

9. Larson JL, Ahijevych K, Gift A, et al. ATS Nursing Research Priorities Subcommittee. American Thoracic Society statement on research priorities in respiratory nursing. Am J Respir Crit Care Med 2006; 174: 471-8.

10. Ambrosino N, Simonds A. The clinical management in extremely severe COPD. Respir Med 2007; 101: 1613-24.

11. Pinnock H, Kendall M, Murray SA, et al. Living and dying with severe chronic obstructive pulmonary disease: multi-perspective longitudinal qualitative study. BMJ 2011; 342: d142. doi: 10.1136/bmj.d142.

12. Curtis JR. Palliative and end-of-life care for patients with severe COPD. Eur Respir J 2008; 32: 796-03.

13. Katz S, Ford AB, Moskowitz RW, Jackson BA, Jaffe MW. Studies of illness in the aged. The index of ADL: a standardized measure of biological and psychosocial function. JAMA 1963; 185: 914-9.

14. Miravitlles M, Murio C, Guerrero T, Gisbert R. Costs of chronic bronchitis and COPD. A 1-year follow-up study. Chest 2003; 123: 784-91.

15. Nielsen R, Johannessen A, Benediktsdottir B, et al. Present and future costs of COPD in Iceland and Norway: results from the BOLD study. Eur Respir J 2009; 34: 850-7.

16. Koleva D, Motterlini N, Banfi P, Garattini L. Healthcare costs of COPD in Italian referral centres: A prospective study. Respir Med 2007; 101: 2312-20.

17. Halpin DM. Health Economics of Chronic Obstructive Pulmonary Disease. Proceedings of the ATS 2006; 3 : 227-33.

18. Lucioni C, Donner CF, De Benedetto F, et al. I costi della broncopneumopatia cronica ostruttiva: la fase prospettica dello Studio ICE (Italian Costs for Exacerbations in COPD). Pharmacoeconomics - Italian Research Articles 2005; 7; 119-34. 
19. Tynan AJ, Lane SJ. COPD: illness severity, resource utilisation and cost. Ir Med J 2005; 98: 41-4.

20. Detournay B, Pribil C, Fournier M, et al. The SCOPE study: health-care consumption related to patients with chronic obstructive pulmonary disease in France. Value Health 2004; 7: 168-74.

21. Skrepnek GH, Skrepnek SV. Epidemiology, clinical and economic burden, and natural history of chronic obstructive pulmonary disease and asthma. Am J Manag Care 2004; 10: s129-38.

22. Nishimura S, Zaher C. Cost impact of COPD in Japan: opportunities and challenges? Respirology 2004; 9: 466-73.

23. Masa JF, Sobradillo V, Villasante C, et al. Costs of chronic obstructive pulmonary disease in Spain: estimation from a population-based study. Arch Broncopneumol 2004: 40: 72-9.

24. Miravitlles M, Murio C, Guerrero T, et al. Pharmacoeconomic evaluation of acute exacerbations of chronic bronchitis and COPD. Chest 2002; 121: 1449-55.

25. Hilleman DE, Dewan N, Malesker M, Friedman M. Pharmacoeconomic evaluation of COPD. Chest 2000; 118: $1278-85$.

26. Rutten van Molken MP, Feenstra TL. The burden of asthma and chronic obstructive pulmonary disease: da- ta from The Netherlands. Pharmacoeconomics 2001; 19 (Suppl 2): 1-6

27. Jansson SA, Andersson F, Borg S, Ericsson A, Jönsson E, Lundbäck B. Costs of COPD in Sweden according to disease severity. Chest 2002; 122: 1994-02.

28. Halpern MT, Stanford RH, Borker R. The burden of COPD in the U.S.A.: results from the Confronting COPD survey. Respir Med 2003; 97 (Suppl C): S81-89.

29. Dal Negro RW, Tognella S, Tosatto R, Dionisi M, Turco P, Donner CF. Costs of chronic obstructive pulmonary disease (COPD) in Italy: The SIRIO study (Social Impact of Respiratory Integrated Outcomes). Respir Med 2008; 102: 92-01.

30. Dal NR, Eandi M, Pradelli L, Iannazzo S. Cost-effectiveness and healthcare budget impact in Italy of inhaled corticosteroids and bronchodilators for severe and very severe COPD patients. Int J Chron Obstruct Pulmon Dis 2007; 2: 169-76.

31. Clini EM, Magni G, Crisafulli E, Viaggi S, Ambrosino $\mathrm{N}$. Home non-invasive mechanical ventilation and long-term oxygen therapy in stable hypercapnic chronic obstructive pulmonary disease patients: comparison of costs. Respiration 2009; 77: 44-50.

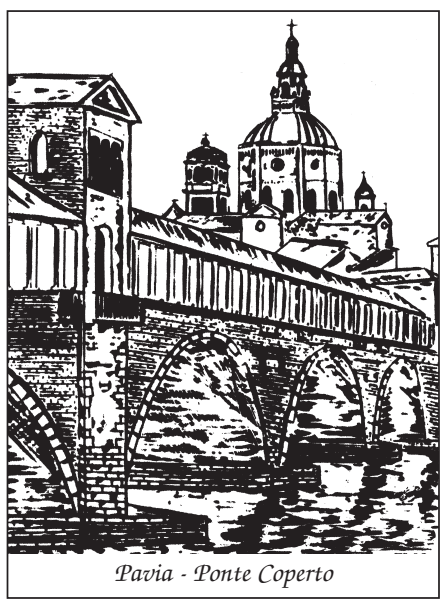

